\title{
Effect of Both Bisphenol - A and Liquorice on Some Sexual Hormones in Male Albino Rats and Illustration of the Effect of Stem Cell Enhancer on Their Actions
}

\author{
Eman G.E. Helal ${ }^{1}$, Dina Alsayed Zaki ${ }^{2}$, Mohamed A. Abdelaziz ${ }^{3}$, Abeer Zakaria ${ }^{1,}$ \\ ${ }^{1}$ Zoology Department, Faculty of Science (Girls), Al-Azhar University-Cairo, Baterij Medical College-KSA, \\ ${ }^{3}$ Physiology Department, Faculty of Medicine, Al-Azhar University-cairo. \\ *Corresponding Author: Eman G.E. Helal, E-mail: emanhelal@ hotmail.com, Mobile: 00201001025364, \\ Orchid.org/0000-0003-0527-7028.
}

\begin{abstract}
Background: Xenoestrogens are a type of xenohormone that imitates estrogen. They can be either synthetic or natural chemical compounds. Synthetic xenoestrogens include some widely used industrial compounds, such as PCBs, bisphenol A (BPA) and phthalates. "Dietary estrogen" is also called phytoestrogen, which is a plantderived xenoestrogen not generated within the endocrine system, but consumed by eating phytoestrogenic plants. Stem cell enhancer (SCE) (StemEnhance $\left.{ }^{\circledR}\right)$ is a novel mobilizer of bone marrow adult stem cells that was shown to increase the number of circulating stem cells.

Objectives: The aim of the current work was to clarify the effect of both BPA and liquorice together on some sexual hormones and illustration of the effect of stem cell enhancer on their actions.

Materials and methods: Thirty male albino rats were used and were divided into three groups: Group I: control (untreated group), group II: rats treated with BPA and liquorice and group III: rats treated with BPA and anise oil in addition to stem cell enhancer. Blood samples were collected for different biochemical investigations.

Results: There was a highly significant increase $(\mathrm{p}<0.01)$ in the level of ALT and AST activities, urea, creatinine, FSH, prolactin, total cholesterol, triglycerides, LDL-C, VLDL, LDL/HDL and TC/HDL. While, there was highly significant decrease $(\mathrm{p}<0.01)$ in HDL-C, total protein, albumin, globulin, testosterone and LH. These results turned back to the normal values after receiving the SCE as compared to normal group.

Conclusion: It could be concluded that phytoestrogen and xenoeostrogen have undesirable effects and it is recommended to minimize the utilization of these compounds to protect people from its hazardous effects.
\end{abstract}

Keywords: BPA, Liquorice, Stem Cell Enhancer, Hormonal assay, Biochemical parameters.

\section{INTRODUCTION}

The impact of endocrine disrupting chemical exposure on human health is receiving increasingly focused attention especially bisphenol A (BPA). BPA is one of the manufacturing compounds that are used in production of different plastic compounds and polycarbonate and become universally used in the production of paper, food and beverage containers, consumer goods and in many other industrial applications ${ }^{(\mathbf{1})}$. Researches showed that BPA has ability to leach out some products including tableware, plastic lining of cans used for food, white dental fillings sealants and polycarbonate babies' bottles. The leaching occurred by exposure of the plastic to high temperatures ${ }^{(2)}$. The adverse effects of BPA are mostly due to its estrogenic activity. Their actions are mediated by endocrine signaling pathways resulting in large changes in the cell functions even at very low concentrations. These changes have deleterious effects on health including prostate and breast cancer. It has been reported that BPA induces oxidative stress in different body organs. Furthermore, other effects of BPA have been recorded such as mitochondrial-mediated apoptosis in the hepatic tissue and inflammatory cytokine dysregulation ${ }^{(3)}$.

The herbs chosen for this study contain phytoestrogens as shown from their chemical constrituents. Licorice, from the dried roots of Glycyrrhiza Glabra L (Fabaceae), is one of the common herbal medicines that are grown and used broadly in different regions of the world. Several countries have used extracted licorice as a sweetening additive in candies, tobacco and beverages. Licorice has many components, including chalcones, flavonoids, glycyrrhizic acid and glycyrrhizin, which is considered the major biologically active one. Previous studies have reported that licorice root has many medical activities such as antimicrobial, antiatherosclerotic, antiulcer, anticancer, anti-viral, antiinflammatory, antioxidant effect and free-radical scavenging activities. It has been used as a medical raw material to reduce weight gain because of its diuretic effect. Also, it was used to increase white blood cell count, as an antidote, as a relaxant and as an expectorant ${ }^{(4)}$. It is proved that licorice is effective in the detoxification and protection of the liver. Moreover, licorice root contains liquiritin apioside, which is a potent antitussive compound.

Stem cell enhancer is a natural stem cell mobilizer that can trigger the release of millions of adult stem cells from bone marrow into the circulation, and its considerable safety allows for a sustained oral daily intake over long periods of time (4). The product we carry is a blend of many compounds extracted from the cyanophyta 
Aphanizomenon flos-aquae (AFA), Undaria pinnatifida, Polygonum multiflorum, and Cordyceps sinensis to support the release of additional stem cells. They may have individual physiological effect or synergistic effects with one another, such as serving as both a releasing agent and migration agent (5). Stem cell therapeutic strategies are being evaluated as an attractive promising approach for liver repair. Several studies have reported the ability of various types of stem cells to improve the pathological outcome of liver cirrhosis and to attenuate the clinical symptom of the disease ${ }^{6}$. They may have an individual physiological effect or synergistic effects with one another, such as serving as both a releasing agent and migration agent ${ }^{(7)}$.

\section{AIM OF THE STUDY}

This study was conducted to clarify the effect of both BPA and liquorice together on some sexual hormones and illustration of the effect of stem cell enhancer on their actions.

\section{MATERIALS AND METHODS}

Thirty male Albino rats of the local strain weighing 110-130 $\mathrm{g}$ were used throughout the experiments. The animals were housed in isolated animal metal cages in a conditioned room in the animal lab of the Physiology Department, Faculty of science, Al-Azhar University.

\section{Ethical approval:}

The study was approved by the Ethics Board of Al-Azhar University.This study was conducted in accordance with ethical procedures and policies approved by Animal Care and Use Committee of Faculty of Medicine, Al-Azhar University, Cairo, Egypt.

Animal were treated according to guidelines for the use and care of laboratory animals in temperature, ventilation, humidity and normal dark / light cycle with free access to water and fed on rodent chow diet all over the period of the work (4 weeks).

\section{Experimental design:}

The rats were divided into three equal groups (10 rats each) as the follows:

Group I (control group): Rats that were maintained on standard rodent chow diet and tap water ad libitum for 30 days.
Group II: Rats received orally liquorice $(1 \mathrm{ml} / \mathrm{kg}$ body weight) and BPA (20 mg $/ \mathrm{kg}$ body weight for 30 days.

Group III: Rats treated by BPA and liquorice in addition to stem cell enhancer $(2.835 \mathrm{mg}$ body weight).

Body weight measurement: Body weight was recorded before and after the experiment.

\section{Blood sampling:}

At the end of the experimental period, the blood samples were collected from the retro-orbital sinus after anesthetizing the rat by ether. Serum was separated to estimate biochemical parameters.

\section{Biochemical analysis}

In the present study, total protein (TP), albumin and $\mathrm{A} / \mathrm{G}$ ratio were measured and estimated. Aspartate aminotransferase (AST) and alanine aminotransferase (ALT) activities, creatinine, urea as well as lipid profile [cholesterol, triglycerides and high-density lipoprotein cholesterol (HDL-C)] concentrations were also determined. All parameters were estimated using Bio Merieux SA kits, France. Ratios of TC/HDL (risk factor 1) and LDL/HDL (risk factor 2) were also calculated after calculation of serum LDL-C (low-density lipoprotein cholesterol) and VLDL (very low density lipoprotein cholesterol) using the Friedwald's ${ }^{(8)}$ and Norbert ${ }^{(9)}$ formulas, respectively as following: Friedewald's equation: LDL $(\mathrm{mg} / \mathrm{dl})=$ TC $-\{\mathrm{HDL}+[\mathrm{TG} / 5]\}$. Norbert equation: $\mathrm{VLDL}=\mathrm{TG} / 5$. Estimation of serum luteinizing hormone (LH), follicles-stimulating hormone $(\mathrm{FSH})$, prolactin $(\mathrm{P})$ and testosterone $(\mathrm{T})$ were determine by using instructions of kit manufacturer. All kits used for hormone assay were from Monobind Inc. (Lake Forest CA 92630, USA).

\section{Statistical analysis}

The results were expressed as Mean \pm SEM. Data were analyzed by T-test and were performed using the Statistical Package (SPSS) program, version 19. The Bonferroni test was used as amethod to compare significance between groups.

\section{RESULTS}

Results of the present study showed insignificant increase in the body weight in the mixture group and treated group Stem Cell Enhancer compared to control rats (Table1).

Table (1): Change of body weight in the control and treated groups

\begin{tabular}{|c|c|l|l|}
\hline $\begin{array}{c}\text { Parameter } \\
\text { \% of body weight change }\end{array}$ & $\begin{array}{c}\text { Control } \\
(\text { mean } \pm \text { SE) }\end{array}$ & $\begin{array}{c}\text { Mixture } \\
(\text { mean } \pm \text { SE) }\end{array}$ & $\begin{array}{c}\text { Mixture and Stem Cell } \\
\text { Enhancer }(\text { mean } \pm \text { SE) }\end{array}$ \\
& $113.2 \pm 0.04$ & $121.4 \pm 2.9^{*}$ & $126.6 \pm 1.3$ \\
$8.1 \%$ & $11.48 \%$ \\
\hline
\end{tabular}

Value represent (mean $\pm \mathrm{SE}$ ) (standard error). ( $\mathrm{p}^{*}<0.05, \mathrm{p}^{* *}<0.01$ as compared to control group). 


\section{Protein profile:}

The present study showed a significant decrease $(\mathrm{p}<0.01)$ in total protein, albumin and globulin in mixture group, while showed insignificant change in total protein, albumin and globulin in stem cell enhancer-treated group when compared to control group (Table 2).

Table (2): Change in protein profile in the control and treated groups

\begin{tabular}{|c|c|c|c|}
\hline Groups & $\begin{array}{c}\text { Control } \\
(\text { mean } \pm \text { SE) }\end{array}$ & $\begin{array}{c}\text { Mixture } \\
(\text { mean } \pm \text { SE) }\end{array}$ & $\begin{array}{c}\text { Mixture and Stem Cell } \\
\text { Enhancer } \\
\text { (mean } \pm \text { SE) }\end{array}$ \\
\hline Parameters & $6.18 \pm 0.09$ & $4 \pm 0.10^{* *}$ & $5.3 \pm 0.11$ \\
Total protein(g/dl) & $3.44 \pm 0,02$ & $-37.3 \%$ & $-14.24 \%$ \\
\hline \%change & $2.78 \pm 0.24$ & $-46.9 \%$ & $2.9 \pm 0.07$ \\
\hline \%lbumin $(\mathrm{g} / \mathrm{dl})$ & $2.1 \pm 0.4 * *$ & $-15.9 \%$ \\
\hline Globulinge & & $-24.5 \%$ & $2.4 \pm 0.03$ \\
$\%$ change & $1.30 \pm 0.21$ & $0.90 \pm 0.03$ & $-13.7 \%$ \\
\hline $\begin{array}{c}\text { Albumin/ Globulin } \\
\% \text { change }\end{array}$ & & $-32.8 \%$ & $1.21 \pm 0.02$ \\
\hline
\end{tabular}

Value represent (mean $\pm \mathrm{SE}$ ) (standard error). ( $\mathrm{p}^{*}<0.05, \mathrm{p}^{* *}<0.01$ as compared to control group).

\section{Liver function tests:}

There was a significant increase $(\mathrm{p}<0.02)$ in the levels of ALT and AST in mixture group and non-significant change in the previous levels in stem cell enhancer group when compared to control rats (Table 3 ).

Table (3): Change in liver function test in the control and treated groups

\begin{tabular}{|c|c|c|c|}
\hline Groups & $\begin{array}{c}\text { Control } \\
(\text { mean } \pm \text { SE) }\end{array}$ & $\begin{array}{c}\text { Mixture } \\
\text { (mean } \pm \text { SE }\end{array}$ & $\begin{array}{c}\text { Mixture and Stem Cell } \\
\text { Enhancer (mean } \pm \text { SE) }\end{array}$ \\
\hline Parameters & $19.8 \pm 2.3$ & $32.7 \pm 0.75^{* *}$ & $29.3 \pm 0.08$ \\
\hline $\begin{array}{c}\text { ALT }(\mathrm{U} / \mathrm{dl}) \\
\% \text { change }\end{array}$ & $23.4 \pm 3.1$ & $40.3 \%$ & $18.5 \%$ \\
\hline $\begin{array}{c}\text { AST }(\mathrm{U} / \mathrm{dl}) \\
\% \text { change }\end{array}$ & & $69.5 \%$ & $31.4 \pm 0.06$ \\
\hline
\end{tabular}

Value represent (mean \pm SE) (standard error). $\left(\mathrm{p}^{*}<0.05, \mathrm{p}^{* *}<0.01\right.$ as compared to control group ).

\section{Lipid profile:}

The present study showed that there was a significant increase $(\mathrm{p}<0.01)$ in all the parameters of lipid profile, except HDL that showed highly significant decrease $(\mathrm{p}<0.01)$ in mixture group and showed insignificant change in stem cell enhancer group when compared to control group (Table 4).

Table (4): Changes in Lipid profile in the control and treated groups

\begin{tabular}{|c|c|c|c|}
\hline Groups & $\begin{array}{c}\text { Control } \\
(\text { mean } \pm \text { SE })\end{array}$ & $\begin{array}{c}\text { Mixture } \\
(\text { mean } \pm \text { SE }\end{array}$ & $\begin{array}{l}\text { Mixture and Stem Cell } \\
\text { Enhancer }(\text { mean } \pm \text { SE) }\end{array}$ \\
\hline $\begin{array}{l}\text { T-CH.(mg/dl) } \\
\text { \% change }\end{array}$ & $142 \pm 2.2$ & $\begin{array}{c}172.6 \pm \mathbf{0 . 0 6}^{* *} \\
\mathbf{2 1 . 8 \%}\end{array}$ & $\begin{array}{l}145.6 \pm 0.9 \\
3.7 \%\end{array}$ \\
\hline $\begin{array}{l}\text { T-G.(mg/dl) } \\
\% \text { change }\end{array}$ & $82 \pm 2.6$ & $\begin{array}{c}100.2 \pm 0.17 * * \\
22.6 \%\end{array}$ & $\begin{array}{c}84.1 \pm 0.71 \\
6.1 \%\end{array}$ \\
\hline $\begin{array}{l}\text { HDL-Cl(mg/dl) } \\
\% \text { change }\end{array}$ & $56 \pm 1.7$ & $\begin{array}{l}38.31 \pm 0.9 * * \\
-31.0 \%\end{array}$ & $\begin{array}{c}48.23 \pm 0.005 \\
-14.2 \%\end{array}$ \\
\hline $\begin{array}{l}\text { LDL-C } \\
\text { \% change }\end{array}$ & $70.6 \pm 1.8$ & $\begin{array}{c}113.4 \pm 0.13^{* *} \\
61.2 \%\end{array}$ & $\begin{array}{c}80.3 \pm 0.07 \\
13.9 \%\end{array}$ \\
\hline $\begin{array}{l}\text { VDL-C } \\
\% \text { change }\end{array}$ & $16.4 \pm 0.5$ & $\begin{array}{c}20.02 \pm 0.04^{* *} \\
25.7 \%\end{array}$ & $\begin{array}{c}16.4 \pm 0.14 \\
2.9 \%\end{array}$ \\
\hline $\begin{array}{l}\text { LDL/HDL } \\
\% \text { change }\end{array}$ & $1.27 \pm 0.04$ & $\begin{array}{l}3.0 \pm 0.06^{* *} \\
136.6 \%\end{array}$ & $\begin{array}{c}1.67 \pm 0.31 \\
31.9 \%\end{array}$ \\
\hline $\begin{array}{l}\text { TC/HDL } \\
\% \text { change }\end{array}$ & $2.56 \pm 2.4$ & $\begin{array}{l}4.62 \pm 0.07 * * \\
76.94 \%\end{array}$ & $\begin{array}{c}3.21 \pm 0.03 \\
19.3 \%\end{array}$ \\
\hline
\end{tabular}

Value represent (mean $\pm \mathrm{SE}$ ) (standard error). ( $\mathrm{p}^{*}<0.05, \mathrm{p}^{* *}<0.01$ as compared to control group). 


\section{Kidney function tests:}

The data in table (5) showed a significant increase (0.01) in urea and creatinine in mixture group, while showed insignificant changes in stem cell enhancer groups as compared to control group.

Table (5): Change in kidney function tests in the control and treated groups

\begin{tabular}{|c|c|c|c|}
\hline Groups & $\begin{array}{c}\text { Control } \\
(\text { mean } \pm \text { SE) }\end{array}$ & $\begin{array}{c}\text { Mixture } \\
\text { (mean } \pm \text { SE }\end{array}$ & $\begin{array}{c}\text { mixture and Stem Cell } \\
\text { Enhancer } \\
\text { (mean } \pm \text { SE) }\end{array}$ \\
\hline Urea(mg/dl) \% change & $40.2 \pm 0.9$ & $66.7 \pm 1.3^{* *}$ & $50.6 \pm 0.06$ \\
& & $62.9 \%$ & $24.4 \%$ \\
\hline $\begin{array}{c}\text { Creatinine(mg/dl) \% } \\
\text { change }\end{array}$ & $0.5 \pm 0.2$ & $0.72 \pm 0.07 * *$ & $0.60 \pm 0.71$ \\
\hline
\end{tabular}

Value represent (mean \pm SE) (standard error). ( $\mathrm{p}^{*}<0.05, \mathrm{p}^{* *}<0.01$ as compared to control group).

\section{Hormones:}

Results of the present study showed a significant increase ( $\mathrm{p}<0.01)$ in the level of prolactin, FSH and LH levels and significant decrease in testosterone level in the mixture group when compared to the normal control animal while showed insignificant changes in stem cell enhancer groups when compared to control group (Table 6).

Table (6): Changes in hormonal profile in the tconrol and treated groups.

\begin{tabular}{|c|c|c|c|}
\hline Groups & $\begin{array}{c}\text { Control } \\
\text { parameters }\end{array}$ & $\begin{array}{c}\text { Mixture } \\
\text { (mean } \pm \text { SE }\end{array}$ & $\begin{array}{c}\text { mixture and Stem } \\
\text { Cell Enhancer } \\
\text { (mean } \pm \text { SE) }\end{array}$ \\
\hline Prolactin (ng/ml\% change & $4.3 \pm 0.07$ & $6.71 \pm 0.07 * *$ & $5.12 \pm 0.02$ \\
& $16.2 \pm 0.6$ & $9.4 \pm 0.16^{* *}$ & $18.1 \%$ \\
\hline Testosterone (ng/ml\% change & & $-39.5 \%$ & $14.43 \pm 0.08$ \\
\hline FSH (mlu/ml\% change & $2.7 \pm 0.07$ & $5.22 \pm 0.95^{* *}$ & $-12.7 \%$ \\
\hline LH (mlu/ml\% change & $10.7 \pm 0.5$ & $92.6 \%$ & $14.8 \%$ \\
\hline & & $-25.51 \pm 0.07 * *$ & $8.94 \pm 0.07$ \\
& & & $-16.1 \%$ \\
\hline
\end{tabular}

Value represent (mean $\pm \mathrm{SE}$ ) (stander error). ( $\mathrm{p}^{*}<0.05, \mathrm{p}^{* *}<0.01$ as compared to control group).

\section{DISCUSSION}

The widespread exposure of human to BPAcontaining products attracted the attention of the scientists to investigate their detrimental effects on the human health. In this work, three compounds are tested; bisphenol A (which is a monomer of polycarbonate plastics), liquorice and stem cell enhancer.

Regarding body weight in the present study, the mixture of bisphenol $\mathrm{A}$ and liquorice increased significantly the body weight. This effect may be attributed to the glycyrrhiza labra. Increase in body weight by glycyrrhiza glabra root extract is in accordance with that reported by Miller ${ }^{(10)}$ who demonstrated that glycyrrhiza glabra inhibits $11 \beta$ hydroxysteroid dehydrogenase and induces excess release of mineralocorticoids, which causes retention of sodium and water that leads to edema and increase in body weight. However, the increased body weight is explained by the improvement in feeding efficiency ${ }^{(11)}$.
Concerning liver function tests in our study, there were adverse effects on the liver of rats i.e., hepatotoxicity due to BPA ingestion in low or large doses that manifests itself in the form of a highly significant increase of hepatic enzymes ALT and AST when compared to the controls. The liver is the major organ for the metabolism and detoxification of xenobiotics, including BPA ${ }^{(\mathbf{1 2})}$. Therefore, the liver is largely exposed to BPA and become susceptible to lower doses than other organs. In humans, the urinary concentration of BPA was associated with abnormal liver function. There are some reports that high doses of BPA cause altered liver weights in mice or rats and decreased the viability of rat hepatocytes. Recently, the oxidative stress was proposed as another adverse cellular effect of BPA in the liver. BPA increased the generation of ROS and induced cellular apoptosis in hepatocytes ${ }^{(13)}$. Previous studies reported that increase in the levels of IL- 6 and TNF- $\alpha$ was observed following BPA treatment. Also, BPA reduced catalase and glutathione peroxidase 3 
(GPX3) expression in the liver and kidney of male mice. Although, ROS can increase proinflammatory cytokines, proinflammatory cytokines themselves can induce oxidative stress ${ }^{(\mathbf{1 4})}$.

Also, liquorice has toxic effect on the liver after G. glabra administration. It causes changes in hepatocyte tissue, congestion and necrosis of hepatocytes in the liver of extract-treated animals could be caused by metabolism of plant extract in the liver (15). Any changes in size and shape of hepatocyte's nucleus could be considered as a sign of increased metabolic activity. Focal necrosis of the liver tissue could be driven from the animal's excessive activity to get rid of the toxicant from its body during the process of detoxification. Also, the liver incapability in regenerating new cells may lead to necrosis (16). After oral administration of glycyrrhizin it is metabolized to glycyrrhetinic acid by intestinal bacteria which contain $\beta$-Dglucuronidase (17). Furthermore, intravenously administered glycyrrhizin is metabolized in the liver by lysosomal $\beta$-D-glucuronidase to 3 monoglucuronide glycyrrhetinic acid. This metabolite is excreted with bile into the intestine, where it is metabolized by bacteria into glycyrrhetinic acid, which can be reabsorbed. AST and ALT elevation was reduced in the animals treated with SCE administration that improved liver function with no significance when compared to the controls. Stem cell therapeutic strategies are being evaluated as an attractive promising approach for liver repair. The ability of SCE aphanizomenon flos-aquae (AFA) to mobilize BMSCs has been reported to help reverse hair color and support overall healing and regeneration ${ }^{(18)}$. Polygonum multiflorum possess important properties for tapping into regenerative and restorative potential of the body. Amelioration of hepatic inflammatory and fibrotic injury via bone marrow stem cell therapy can promote the proliferation of residual hepatocytes.

Regarding proteins profile in the present study, the mixture of bisphenol $\mathrm{A}$ and liquorice caused toxicity and inflammation of liver which induced significant decrease in protein profile. Decreased serum protein biosynthesis in the liver of rats treated with BPA may be attributed to the formation of BPA adducts. De Flora $\boldsymbol{e t}$ al. ${ }^{(19)}$ reported the ability of BPA to form DNA adducts in vitro in an acellular system and in vivo in rodent liver. Atkinson and Roy (20) found that BPA is converted to bisphenol oquinone, which might bind to DNA. When this occur the transcription of DNA to mRNA will be impaired resulting ultimately in the inhibition of protein synthesis. The hypoproteinemia observed in the present results revealed the hepatotoxic nature of BPA in liver cells. The synthesis of albumin is depressed in a variety of diseases particularly those of the liver (21). It is possible that the chemical constituents of the plant parts, majorly the alkaloids are responsible for this negative effect. When the animals treated with SCE, AST and ALT elevation were reduced to a value close to the normal. This may be due to the antioxidant activity of some stem enhance constituents that exhibited a hepatoprotective effect against liver damage ${ }^{\text {(22) }}$.

In regard to Lipids profile results of the present study revealed a disturbance in lipid profile as reflected by the significant increase all the parameters of lipid profile, except HDL-C level which showed a significant decrease in mixture-treated groups when compared to control. Lipid metabolism is affected once there is damage since the disturbance of cell membrane integrity is likely to cause some membrane lipids to be released into circulation. Also, lipid peroxidation results from the imbalance between pro-oxidant and antioxidant chemical species ${ }^{(23)}$. These oxidative processes produce free electrons, $\mathrm{H}_{2} \mathrm{O}_{2}$ and reactive oxygen species (ROS) are known to alter lipid profile activity. Lipid peroxidation usually leads to the formation of peroxyl radicals, which are central species in the peroxidation chain reaction. Such reactive oxygen species as hydroxyl and superoxide radicals are known to provoke severe cellular alterations resulting in cell damage or death, due to their high reactivity. These species attack such important cell constituents as proteins, lipids and nucleic acids. The lipid peroxides that accumulate due to lipid peroxidation are known to be very harmful to cells and tissues ${ }^{(24)}$. BPA can induce estrogenic activity in treated groups, where estrogens have a significant effect on serum cholesterol. The effect on cholesterol is probably due to an action of the hormone on the lipoproteins associated with cholesterol in the circulation, so altering the level of serum cholesterol ${ }^{(25)}$. BPA had also found to stimulate lipid accumulation and upregulate genes involved in lipid metabolism in adipocytes (26). Mechanistically, liquorice or environmental BPA acts like the estrogen receptors and do estrogen action. Both BPA (xenoestorgen) and liquorice (phytoestrogen) are a well-known endocrine-disrupting chemical that bind to the estrogen receptors (ER alpha and ER beta) and disrupt the lipid profile. Administration of higher estrogen in diet may be the reason for the incidence of myocardial infarction and other complications of arteriosclerotic diseases ${ }^{(27)}$. Meanwhile, stem celltreated group showed improvement of lipid profile with no significance when compared to the controls. It may be related to cellular protection effect of polygonum multiform (constituent in stem enhance), which reduces lipid peroxidation by up-regulating of cellular antioxidants and decrease MDA concentration. Sanaei et $\boldsymbol{a l} .{ }^{(28)}$ stated that blue-green 
algae inhibits intestinal cholesterol absorption, decreases the hepatic lipids and leads to attenuation of plasma total cholesterol and triglycerides concentrations. Additionally, Polygonum multiflorum (PM) was found to possess an antiatherosclerotic and hypolipidemic activity ${ }^{(29)}$.

Concerning kidney function, the results of this study demonstrated that the rats of the mixture group showed significant increase of the level of urea and creatinine. In this study the kidneys of rats were also intoxicated by BPA, which resulted in a highly significant increase in creatinine and urea concentrations compared to the controls. BPA can cause injury in the kidney and other organs by forming reactive oxygen species (ROS). Oxidative stress can lead to chronic inflammation, which in turn could mediate most chronic diseases. The adverse effects of BPA are largely related to its estrogenic activity where BPA is an estrogenic endocrine disruptor molecule of phenolic structure, which has renal elimination and builds up when the glomerular filtration rate decreases ${ }^{(30)}$. In the rats administrated with G. glabra extract at different concentrations, the kidney showed massive congestive changes and a few necrosis of the nuclei in the epithelial cells of renal tubules. In addition, mild interstitial lymphoplasmacytic nephritis was seen in the kidney of the plant-administrated groups. After G. glabra administration, the toxicity on the kidney appeared in the form of dilation of urinary space in the renal glomerulus as well as dilation of various urinary tubules lumen in the kidney. These changes may be in relation with the hypertension caused by decreased 11B-HSD2 activity. This enzyme is responsible for the renal conversion of cortisol to cortisone. Thus, licorice leads to activation of renal mineralocorticoid receptors by cortisol, resulting in a state of apparent mineralocorticoids excess and therefore large amounts of licorice may result in severe hypertension, hypokalemia and other signs of mineralocorticoid excess and also inhibitory effects of $18 \beta$-glycyrrhetinic acid (one of the ingredients of Glycyrrhiza glabra) on gap junction channels of arteriolar smooth muscle, endothelial cells, renal pelvis, ureter and mesenteric small arteries ${ }^{(31)}$ that probably cause dysfunction of urinary tract smooth muscle and consequently give back and retort the urea up to pelvis and kidney. However, treatment with stem cell enhancer significantly improved creatinine and urea levels. This may be due to its antioxidant properties that improved renal functions via attenuating an oxidative stress-mediated decline in GFR and renal hemodynamics ${ }^{(30)}$.

As regards hormones in the present study, the mixture of bisphenol $\mathrm{A}$ and liquorice caused hormonal disturbances. There was a significant increase in FSH and prolactin while there were significant decrease in testosterone and LH levels. The adverse effects of BPA are largely related to its estrogenic activity and resulted in disturbances to the reproductive functions ${ }^{(31)}$. The exposure of animal to BPA elucidates multiple effects on the male and female reproductive system in various animal models. Different doses of BPA caused inhibition in spermatogenesis. BPA caused a decrease in sperm count and motility and also affected sperm morphology of adult male rats. BPA was associated with declined semen quality and increased sperm DNA damage and this also supports the toxicity of BPA on germ cell ${ }^{(32)}$. Nakamura et al. ${ }^{(33)}$ who stated that BPA decreased the expressions of steroidogenic acute regulatory (StAR) protein and steroidogenic enzymes like cholesterol side chain cleaving enzyme [P450sce (CYP11A1), P45017, and 17_-HSD mRNA] dose-dependently. Therefore, the decreased expression of steroidogenic enzymes and StAR protein included in testosterone synthesis might be primarily related to the decreased testosterone levels as a result of BPA treatment. BPA can induce hyperlactatemia which alter estrogen receptor and/or estrogen-responsive genes that affect the lactrophes in rats. They recorded an increase of prolactin releasing factor (PRF) which is produced by a subpopulation in intermediate lobe cells that induce PRL secretion. PRF-producing cells and intact posterior pituitary, which are targeted by esterogen-induced rise in PRL secretion, has also hypothalamic actions so that they can alter levels of progesterone receptors experession within the mediobasal hypothalamus. This induced change in neural systems could impact upon gondotrophin secretion. The regulation of spermatogenesis by FSH and testosterone occurs by the action of these hormones on the Sertoli cells and the action of testosterone is necessary for spermatogenesis. Loss of receptor activity from Sertoli cells is thus responsible for a whole range of testicular abnormalities. Helal et al. ${ }^{(34)}$ found that liquorice reduces serum testosterone in healthy men. Also, liquorice inhibits $6 \quad \beta$-hydroxy steroid dehydrogenase and stimulate aromatase resulting in reduced serum testosterone. Liquorice reduced the serum testosterone level and affected androgen metabolism by inhibiting the enzyme $\beta-6$ HSD and 17- $\beta$ HSD hydroxysteroid dehydrogenase or by stimulating aromatase. Therefore, it was proposed that liquorice causes the deficiency in serum testosterone, glabridin, the major isoflavone in liquorice and many other phenols such as liquiritigenin, liquiritin, isoliquiritigenin, isoliquiritin, glabridin and formononetin that are responsible for phytoestrogen activity and estrogenic properties, which cause hormonal disturbance and decrease in sperm count. Meanwhile, SCE recorded a significant improvement in the value of hormones 
and elevated its level as compared to the mixturetreated animals this may be attributed to the ability of SCE to modulate serum hormons, urinary execration of estrogen metabolites and phytoestrogens ${ }^{(35)}$. Also blue green algae has multiple beneficial effects in improving productive and reproductive performance of animal poultry, testosterone level and fertility. Also, it significantly increased testicular function, body weights with normal seminiferous tubules and Leydig cell numbers. The antioxidant components of Spirulina (blue green algae) such as alpha-tocopherol (Vitamin E), ascorbic acid (Vitamin C) and selenium improved the testicular functions and sperm quality ${ }^{(35)}$.

\section{CONCLUSION}

It could be concluded that phytoestrogen and xenoeostrogen have undesirable effects and it is recommended to minimize the utilizing of these compounds to protect people from its hazardous effects.

\section{REFERENCES}

1. Brotons JA, Olea-Serrano MF, Villalobos M et al. (1995): Xenoestrogens released from lacquer coatings in food cans. Environ. Health. Perspect., 103: 608-612.

2. Le H H, CarlsonE M, Chua J P et al. (2008): Bisphenol $\mathrm{A}$ is released from polycarbonate drinking bottles and mimics the neurotoxic actions of estrogen in developing cerebellar neurons. Toxicol. Lett., 176: 149-156.

3. Abdelzaher Y W, Ali M D, Khalil BW (2018): Could Licorice prevent Bisphenol A-Induced Biochemical,Histopathological and Genetic Effects in the Adult Male Albino Rats? Ain Shams Journal of Forensic Medicine and Clinical Toxicology, 30: 7387.

4. Rahnama M, Mehrabani D, Japoni S et al. (2013): The healing effect of licorice (Glycyrrhiza glabra) on Helicobacter pylori infected peptic ulcers. J. Res. Med. Sci., 18: 532-3.

5. Jensen GS, Hart AN, Zaske LA et al. (2007): Mobilization of human CD34+ CD133+ and CD34+ CD133(-) stem cells in vivo by consumption of an extract from Aphanizomenon flos-aquae-related to modulation of CXCR4 expression by an 1-selectin ligand? Cardiovasc. Revasc. Med., 8: 189-202.

6. Agaev B, Agaev R, Popandopoulo A et al. (2014): Clinical efficacy of autologous mesenchyme multipotential stem cells transplantation in the liver cirrhosis and portal hypertension treatment. Georgian Med News, 6:39-45.

7. Jensen G S, HartAN, Zaske L A et al. (2007): Mobilization of human CD34+ CD133+ and CD34+ CD133(-) stem cells in vivo by consumption of an extract from Aphanizomenonflos-aquae-related to modulation of CXCR4 expression by an 1-selectin ligand? Cardiovasc Revasc Med., 8: 189-202.
8. Friedwald's WT, Levy RI, Fredrickson DS et al. (1999): Estimation of the concentration of lowdensity lipoprotein cholesterol in plasma, without use of the preparative ultracentrifuge. Clin. Chem., 18: 499-502.

9. Norbert WT (1995): Clinical guide to laboratory tested.3rd ed.saunders W.B.,company, philadephi. https://onlinelibrary.wiley.com/doi/abs/10.1111/j.15 37-2995.1995.tb03571.

10. WHO (2010): WHO laboratory manual for the examination and processing of human semen. Fifth ed. https://apps.who.int/iris/handle/10665/44261

11. Miller I (1998): Herbal medicine: Selected clinical considerations focusing on known or potential drugherb interaction. Arch. Inter Med., 158: 2200-2211.

12. Ott M, Gogvadze V, Orrenius S et al. (2007): Mitochondria, oxidative stress and cell death. Apoptosis, 12: 913-922.

13. Helal E G, Al Jalaud AN, EInemr MG et al. (2016): Effects of Recovery Period and Stem Cell Enhancer on Bisphenol A Treated Female Albino Rats. The Egyptian Journal of Hospital Medicine, 63: 238- 247.

14. Turrens JF (1997): Superoxide production by the mitochondrial respiratory chain. Biosci Rep., 17: 3-8.

15. Bindhumol V, Chitrak C, Mathur PP (2003): Bisphenol A induces reactive oxygen species generation in the liver of male rats. Toxicology, 188: 117-124.

16. Asahi J, Kamo H, Baba $\mathrm{R}$ et al. (2010): Bisphenol A induces endoplasmic reticulum stress-associated apoptosis in mouse non-parenchymal hepatocytes. Life Sci., 87: 431-438.

17. Kabuto $H$, Hasuike $S$, Minagawa $N$ et al. (2003): Effects of bisphenol A on the metabolisms of active oxygen species in mouse tissues. Environ Res., 93: 31-35.

18. Moon MK, Kim J, Jung IK et al. (2012): Bisphenol A Impairs Mitochondrial Function in the Liver at Doses below the No Observed Adverse Effect Level. J Korean Med Sci., 27 (6): 644-652.

19. Hattori M, Sakamoto $T$, Yamagishi T et al. (1985): Metabolism of glycyrrhizin by human intestinal flora. II. Isolation and characterization of human intestinal bacteria capable of metabolizing glycyrrhizin and related compounds. Chem Pharm Bull, 33: 210-217

20. Kurosawa T, Hiroi H, Tsutsumi $O$ et al. (2002): The activity of bisphenol A depends on both the estrogen receptor subtype and the cell type. Endocr J., 49:465-471.

21. González - Parra E, Herrero JA, Elewa U et al. (2013): Bisphenol A in Chronic Kidney Disease. https://www.hindawi.com/journals/ijn/2013/437857/

22. Kuriakose G (2008): Evaluation of Renoprotective Effect of Aphanizomenonflos-aquae on CisplatinInduced Renal Dysfunction in Rats. Renal Failure, 30: 717-725.

23. Tiez NW (1987): Fundamentals of clinical chemistry. $3^{\text {rd }}$ edition. Philadelphia: W.B. Saunders; Pp: 676.

24. Elmalawany A, Tarek A, Salem T et al. (2014): Effect of blue-green algae on some biochemical and hematological markers in mice. International Journal of Advanced Research, 2 (2): 568-574. 
25. Nadal A, Alonso-Magdalena $\mathbf{P}$, Soriano $\mathbf{S}$ et al. (2009): The pancreatic beta-cell as a target of estrogens and xenoestrogens: implications for blood glucose homeostasis and diabetes. Mol Cell Endocrinol., 304: 63-68.

26. Xie XH, Liao H, Dang W et al. (2009): Downregulation of hepatic HNF 4 alpha gene expression during hyperinsulinemia via SREBPs. Mol Endocrinol., 23: 434-443.

27. Marmugi A, Ducheix S, Lasserre F et al. (2012): Low doses of bisphenol A induce gene expression related to lipid synthesis and trigger triglyceride accumulation in adult mouse liver. Hepatology, 55: 395-407.

28. Sanaei M, Ebrahimi M, Banazadeh Z et al. (2015): Consequences of Aphanizomenon Flos-aquae (AFA) extract (StemtechTM) on metabolic profile of patients with type 2 diabetes. Journal of Diabetes \& Metabolic Disorders, 14 (50): 1-7.

29. Liu L, Liao Z, Yin D et al. (2010): The protective effects of Polygonum multiform stilbene glycoside conditioning in an ischemia/reperfusion model of HUVECs. Acta Pharmacologica Sinica, 31: 405-412.

30. Kourouma A, Quan C, Duan P et al. (2015): Bisphenol A Induces Apoptosis in Liver Cells through Induction of ROS. http://dx.doi.org/10.1155/ 2015/901983.

31. Schecter A, Malik N, Haffner D et al. (2010): Bisphenol A (BPA) in US food. Environ. Sci. Technol., 44 (24): 9425-9430.

32. Meeker J D, Shelley E, Thomas LT et al. (2010): Semen quality and sperm DNA damage in relation tourinary bisphenol A among men from an infertility clinic. Reproductive Toxicology, 30: 532-539.

33. Nakamura $\mathrm{D}$, Yanagiba $\mathrm{Y}$, Duan $\mathrm{Z}$ et al. (2010):Bisphenol A may cause testosterone reduction by adversely affecting both testis and pituitaryolsystems similar to estradiol. Toxicol. Lett., 194: 16-25.

34. Helal G E, El-Aleem AM, Ahmed S S (2019): Comparison between Sesame Oil and Glycyrrhiza Glabra Effect as Phytoestrogen on Male Albino Rats. The Egyptian Journal of Hospital Medicine, 75 (4): 2550-2555.

35. Shanmugapriya B, Babu SS, HariharanT et al. (2015): Dietaryadministration of Spirulina platensis as probiotics ongrowth performance and histopathology in broiler chicks. Int. J. Recent Scient. Res., 6: 2650-2653. 